\title{
Effect of Lifestyle Modification Module on Patients' Compliance Postoperative Bariatric Surgery
}

\author{
Ahmed Elsayed Ibrahiem¹, Salwa Samir Kamel², Asmaa Abdel Rahman Abdel Rahman ${ }^{3}$, Amr Hamed Afifi \\ ${ }^{1}$ Assistant Lecturer, ${ }^{2}$ Professor, ${ }^{3}$ Assistant Professor, Medical Surgical Nursing Department, Faculty of Nursing, \\ Ain Shams University, Cairo, Egypt, ${ }^{4}$ General Surgery Department, Faculty of Medicine, \\ Ain Shams University, Cairo, Egypt
}

\begin{abstract}
Background: Obesity is a grave public health threat, more serious even than the opioid epidemic. It is associated with increased risk of several chronic diseases. Bariatric surgery is an effective and safe technique for the treatment of morbid obesity and co-morbidities related to obesity.

Objective: This study aimed to evaluate the effect of lifestyle modification module on patients' compliance postoperative bariatric surgery.

Method: A quasi experimental design was utilized for the study. A purposive sample of 104 patients with postoperative bariatric surgery who are selected according to certain inclusion criteria.

Results: There was significant improvement in patients' compliance post implementation of lifestyle modification module where the pre compliance mean score was $21.04 \pm 8.07$ and the post mean score was $33.59 \pm 8.34$.

Conclusions: Lifestyle modification module has positive effect on improving patients' compliance postoperative bariatric surgery. This demonstrates that the module is an effective intervention for postoperative counseling to improve bariatric surgery outcomes.
\end{abstract}

Keywords: Postoperative bariatric surgery, lifestyle modification, patient's compliance.

\section{Introduction}

Obesity has been recognized as a universal global health problem, described as an epidemic by the World Health Organization (WHO). It is a chronic, life-limiting disease, which is associated with a number of serious health conditions such as type 2 diabetes mellitus, cardiovascular disease, high blood pressure, obstructive sleep apnea,asthma, osteoarthritis, and some types of cancer $^{[1,2]}$. Bariatric surgery is increasingly recognized as the most effective treatment for individuals who

\section{Corresponding Author:}

\section{Ahmed Elsayed Ibrahiem}

Assistant Lecturer,Medical Surgical Nursing

Department, Faculty of Nursing, Ain Shams University, Cairo, Egypt

e-mail: dr.ahmed.elsayed@nursing.asu.edu.eg are severely obese. Bariatric surgery not only helps in weight reduction, but also improves obesity-related medical conditions and consequently increases the quality of life $\mathrm{e}^{[3]}$.

Worldwide, the total number of bariatric surgery performed in 2014 consisted of 579,517 surgical operations. Compared with 2017, the total number of metabolic and bariatric procedures performed in the united states in 2018 increased from approximately 228,000 to $252,000^{[4,5]}$.

Patients undergoing bariatric surgery are required to adhere to the postsurgical behavioral recommendations that includes; following specific eating and drinking behaviors; exercise regularly; take medication/ supplements daily; and attend follow-up medical appointments for regular monitor and evaluation ofhealthstatus ${ }^{[6,7]}$. 
It is recommended that patients receive lifestyle modification instructions in the form of a discussion or seminar, booklet or through support groups, educational sessions and one-to-one discussions that provides information of recovery and lifestyle behaviors change ${ }^{[8,9]}$.

\section{Method}

In the present study, quantitative and evaluative approach was used. Research design was quasi experimental: one group pre test - post test. Study was conducted inbariatric surgery outpatient clinic and bariatric surgery department at El-Demerdash Hospital which affiliated to Ain Shams University, Cairo, Egypt.

The sample of 104 postoperative patients with bariatric surgery. Type I error with significant level alpha (a) $=0.05$ (confidence level 95\%). The inclusion criteria were: patients' one month postoperative bariatric surgery, age over 18 years, from both sexes, obesity related co-morbidity.

The structured questionnaire was administered.

1. Demographic characteristics and patients' clinical data.

2. (A) Postoperative compliance assessment tool, developed by the researcher using the related literatures (American Society for Metabolic and Bariatric Surgery Surgery ${ }^{[10]}$; still et $\mathrm{a}^{[11]}$ and Kumar and Gomes ${ }^{[12]}$ ). (B) Medication Adherence Rating Scale (MARS): adopted from (Thompson et al, 2000 ${ }^{[13]}$ ). (C) Perceived Stress Scale (PSS): adopted from (Cohen et al., 1983 ${ }^{[14]}$ ). (D) Bariatric Analysis and Reporting Outcome System (BARO) and quality of life questionnaire: adopted from (Moorehead et al., 2003 ${ }^{[15]}$ ).

Data collection started by selecting patients who are met the inclusion criteria, informed consent was taken followed by the pretest and distribution of lifestyle modification module. Patients' tools were filled in by the researchers or by the patients according to patients' educational level.

Patients followed and evaluated after six months post sessions. Data collection process starting at December 2018 until the end of September 2019.

Statistical analysis was performed with SPSS for window, version 20.0 Armonk, NY: IBM Crop. Data analysis was done using $\mathrm{A}$ chi-square test $\mathrm{x}^{2}$ and the values were considered statistically significant when p-value $<0.05$.

\section{Results}

Patients' Characteristics: Table (1) shows the mean age of all patients was $32.57 \pm 6.18$ years. The study participants include 78 female (75\%), 75 urban (72.1\%), 51 diploma education (49\%), 81 not working (77.9\%) and 67 married (64.4\%).

Regarding clinical data: Table (2) illustrates that 96 suffered from chronic disease $(92.3 \%), 85$ were obese (81.7\%), 56 were between $40 \mathrm{~kg}^{2}<50 \mathrm{~kg}^{2}(53.8 \%)$ of body mass index, 100 patients followed program before to lose weight $(96.2 \%), 52$ diet regimen only $(50 \%)$ and 101 gain weight $(97.1 \%)$.

Table(3) demonstrates significance difference in total compliance post implementation of lifestyle modification module where mean score pre module implementation was $(9.51 \pm 3.32,3.53 \pm 3.27,3.95 \pm 1.27$, $3.50 \pm 1.51,21.04 \pm 8.07)$ and post implementation of lifestyle modification module was $(13.82 \pm 3.28$, $9.06 \pm 3.19, \quad 5.58 \pm 1.24, \quad 4.48 \pm 0.85, \quad 33.59 \pm 8.34)$ respectively.

Table (4) illustrates significant differences in total mean scores of patients' compliance with medication, perceiving stress and Bariatric Analysis and Reporting Outcome System (BARO): quality of life post implementation of lifestyle modification module with $95 \%$ confidence interval 1.542-2.164, 2.063-2.349, 2.133-2.867 respectively.

Table (1): Percentage distribution of the studied patients according to their demographic characteristics $(n=104)$.

\begin{tabular}{|l|c|c|}
\hline \multirow{2}{*}{ Items } & \multicolumn{2}{|c|}{ Studied Patients } \\
\cline { 2 - 3 } & $\mathbf{N}$ & \% \\
\hline Age & 17 & 16.3 \\
\hline $18<30$ & 64 & 61.5 \\
\hline $30<40$ & 17 & 16.3 \\
\hline $40<50$ & 6 & 5.9 \\
\hline$\geq 50$ & \multicolumn{2}{|c|}{$32.57 \pm 6.18$} \\
\hline Mean \pm SD & \multicolumn{2}{|c|}{} \\
\hline Gender & 26 & 25.0 \\
\hline Male & 78 & 75.0 \\
\hline Female
\end{tabular}




\begin{tabular}{|l|c|c|}
\hline \multirow{2}{*}{ Items } & \multicolumn{2}{|c|}{ Studied Patients } \\
\cline { 2 - 3 } & N & \% \\
\hline Residence & 29 & 27.9 \\
\hline Rural & 75 & 72.1 \\
\hline Urban & \multicolumn{2}{|l}{} \\
\hline Educational level & 22 & 21.2 \\
\hline Can't read and write & 51 & 49.0 \\
\hline Diploma education & 31 & 29.8 \\
\hline Higher education & 7 & 6.7 \\
\hline Occupational state & 14 & 13.5 \\
\hline Free work & 81 & 77.9 \\
\hline Governmental work & 2 & 1.9 \\
\hline Not working & 27 & 26.0 \\
\hline Others & 67 & 64.4 \\
\hline Marital status & 10 & 9.6 \\
\hline Single & \multicolumn{2}{|}{} \\
\hline Married & \multicolumn{2}{|l}{} \\
\hline Widow/Divorced & \multicolumn{2}{|l}{} \\
\hline
\end{tabular}

Table (2): Percentage distribution of the studied patients regarding clinical data $(n=104)$.

\begin{tabular}{|l|c|c|}
\hline Present history & N & $\%$ \\
\hline \multicolumn{2}{|l|}{ Suffers from chronic diseases } \\
\hline Yes & 96 & 92.3 \\
No & 8 & 7.7 \\
\hline
\end{tabular}

\begin{tabular}{|c|c|c|}
\hline Present history & $\mathbf{N}$ & $\%$ \\
\hline \multicolumn{3}{|l|}{ Chronic diseases $(*)$} \\
\hline Obesity & 85 & 81.7 \\
\hline Hypertension & 27 & 26.0 \\
\hline Diabetes Mellitus & 34 & 32.7 \\
\hline Others (ex. thyroid problems) & 14 & 13.5 \\
\hline \multicolumn{3}{|l|}{ Body Mass Index (BMI) } \\
\hline $30 \mathrm{~kg} 2<35 \mathrm{~kg} 2$ & 0 & 0 \\
\hline $35 \mathrm{~kg} 2<40 \mathrm{~kg} 2$ & 14 & 13.5 \\
\hline $40 \mathrm{~kg} 2<50 \mathrm{~kg} 2$ & 56 & 53.8 \\
\hline$\geq 50 \mathrm{~kg} 2$ & 34 & 32.7 \\
\hline \multicolumn{3}{|c|}{ Follow program before to lose weight } \\
\hline Yes & 100 & 96.2 \\
\hline No & 4 & 3.8 \\
\hline \multicolumn{3}{|c|}{ The program followed before consist of: } \\
\hline $\begin{array}{l}\text { Diet only. } \\
\text { Diet and physical exercise. } \\
\text { Body slimming medicines and } \\
\text { herbals. }\end{array}$ & $\begin{array}{c}52 \\
47 \\
5\end{array}$ & $\begin{array}{c}50.0 \\
45.2 \\
4.8\end{array}$ \\
\hline \multicolumn{3}{|c|}{ Outcomes of the previous programs: } \\
\hline $\begin{array}{l}\text { Weight loss } \\
\text { Weight gain }\end{array}$ & $\begin{array}{c}3 \\
101\end{array}$ & $\begin{array}{c}2.9 \\
97.1\end{array}$ \\
\hline
\end{tabular}

* Patients may have more than one disease or take more than one medications.

Table (3): Differences in total compliance among studied patients pre and post implementation of lifestyle modification module $(n=104)$

\begin{tabular}{|c|c|c|c|c|c|c|c|c|c|c|}
\hline \multirow{2}{*}{$\begin{array}{l}\text { Items of } \\
\text { compliance }\end{array}$} & \multicolumn{2}{|c|}{ Good } & \multicolumn{2}{|c|}{ Fair } & \multicolumn{2}{|c|}{ Poor } & \multirow{2}{*}{ Mean \pm SD } & \multicolumn{2}{|c|}{ Chi-square } & \multirow{2}{*}{$95 \% \mathrm{CI}$} \\
\hline & $\mathbf{N}$ & $\%$ & $\mathbf{N}$ & $\%$ & $\mathbf{N}$ & $\%$ & & $\mathbf{X}^{2}$ & P-value & \\
\hline \multicolumn{11}{|c|}{ Compliance to diet after bariatric surgery } \\
\hline Pre & 11 & 10.6 & 28 & 26.9 & 65 & 62.5 & $9.51 \pm 3.32$ & \multirow{2}{*}{69.076} & \multirow{2}{*}{0.001} & \multirow{2}{*}{$1.409-1.944$} \\
\hline Post & 58 & 55.8 & 34 & 32.7 & 12 & 11.5 & $13.82 \pm 3.28$ & & & \\
\hline \multicolumn{11}{|c|}{ Compliance to physical exercise } \\
\hline Pre & 0 & 0.0 & 7 & 6.7 & 97 & 93.3 & $3.53 \pm 3.27$ & \multirow{2}{*}{80.004} & \multirow{2}{*}{0.001} & \multirow{2}{*}{$2.383-2.735$} \\
\hline Post & 8 & 7.7 & 61 & 58.7 & 35 & 33.7 & $9.06 \pm 3.19$ & & & \\
\hline \multicolumn{11}{|c|}{ Compliance to sleep and rest instructions } \\
\hline Pre & 40 & 38.5 & 30 & 28.8 & 34 & 32.7 & $3.95 \pm 1.27$ & \multirow{2}{*}{40.735} & \multirow{2}{*}{0.001} & \multirow{2}{*}{$1.195-1.687$} \\
\hline Post & 85 & 81.7 & 10 & 9.6 & 9 & 8.7 & $5.58 \pm 1.24$ & & & \\
\hline \multicolumn{11}{|c|}{ Compliance to stop smoking activities } \\
\hline Pre & 0 & 0.0 & 4 & 23.5 & 13 & 76.5 & $3.53 \pm 1.70$ & \multirow{2}{*}{0.151} & \multirow{2}{*}{0.697} & \multirow{2}{*}{$2.579-2.892$} \\
\hline Post & 0 & 0.0 & 5 & 29.4 & 12 & 70.6 & $5.06 \pm 1.82$ & & & \\
\hline
\end{tabular}




\begin{tabular}{|c|c|c|c|c|c|c|c|c|c|c|}
\hline \multirow{2}{*}{$\begin{array}{l}\text { Items of } \\
\text { compliance }\end{array}$} & \multicolumn{2}{|c|}{ Good } & \multicolumn{2}{|c|}{ Fair } & \multicolumn{2}{|c|}{ Poor } & \multirow{2}{*}{ Mean \pm SD } & \multicolumn{2}{|c|}{ Chi-square } & \multirow{2}{*}{$95 \%$ CI } \\
\hline & $\mathbf{N}$ & $\%$ & $\mathbf{N}$ & $\%$ & $\mathbf{N}$ & $\%$ & & $\mathrm{X}^{2}$ & P-value & \\
\hline \multicolumn{11}{|c|}{ Compliance to follow-up } \\
\hline Pre & 51 & 49.0 & 34 & 32.7 & 19 & 18.3 & $3.50 \pm 1.51$ & \multirow{2}{*}{26.752} & \multirow{2}{*}{0.001} & \multirow{2}{*}{$1.075-1.514$} \\
\hline Post & 84 & 80.8 & 18 & 17.3 & 2 & 1.9 & $4.48 \pm 0.85$ & & & \\
\hline \multicolumn{11}{|c|}{ Total compliance } \\
\hline Pre & 1 & 1.0 & 19 & 18.3 & 84 & 80.8 & $21.04 \pm 8.07$ & \multirow{2}{*}{62.514} & \multirow{2}{*}{0.001} & \multirow{2}{*}{$1.614-2.151$} \\
\hline Post & 16 & 15.4 & 60 & 57.7 & 28 & 26.9 & $33.59 \pm 8.34$ & & & \\
\hline
\end{tabular}

Table (4): Differences in mean score regarding medication compliance, perceiving stress and Bariatric analysis and reporting outcome system (BARO) and Quality of life questionnaire among studied patients pre and post implementation of lifestyle modification module $(n=104)$.

\begin{tabular}{|l|c|c|c|c|c|}
\hline \multirow{2}{*}{ Items } & \multirow{2}{*}{$\begin{array}{c}\text { Pre (1 month) } \\
\text { Mean } \pm \text { SD }\end{array}$} & \multirow{2}{*}{$\begin{array}{c}\text { Post (6 months) } \\
\text { Mean } \pm \text { SD }\end{array}$} & \multicolumn{2}{|c|}{ Chi-square } & \multirow{2}{*}{ 95\% CI } \\
\cline { 4 - 6 } & $\mathbf{X}^{\mathbf{2}}$ & P-value & \\
\hline Total medication adherence. & $4.11 \pm 2.36$ & $6.61 \pm 1.84$ & 55.548 & 0.001 & $1.542-2.164$ \\
\hline Total perceived stress & $21.90 \pm 6.27$ & $16.22 \pm 5.19$ & 32.385 & 0.001 & $2.063-2.349$ \\
\hline $\begin{array}{l}\text { Bariatric analysis and reporting outcome } \\
\text { system (BARO): Quality of life questionnaire. }\end{array}$ & $1.57 \pm 0.89$ & $5.00 \pm 1.47$ & 41.568 & 0.001 & $2.133-2.867$ \\
\hline
\end{tabular}

\section{Discussion}

This study evaluates the effect of lifestyle modification module on patients' compliance postoperative bariatric surgery and found that it produced a significant improvement in patients' compliance. The hypothesis of the study demonstrated that the module is an effective tool to help this group of bariatric surgery patients to modify their lifestyle.

The study findings illustrates that, more than half of patients achieved good level of compliance with diet instructions post implementation of lifestyle modification module. This result may be due to the motivation and support provided by researchers and the desire of patients to achieve good outcomes of operation and appropriate weight loss. In addition to improved patients' skills in preparing foods, selecting types and eliminating prohibited diet.

This result agree with Kalarchian et al. who found that there was statistically significance difference in weight change of the studied patients at 4 months and 6 months after surgery post eating guidelines interventions ${ }^{[16]}$. While Toussi, Fujioka and Colemanstated that the non compliance was higher after the surgery regarding diet recommendations ${ }^{[17]}$.

There was statistically significance difference in patients' compliance post implementation of lifestyle modification module. This may be due to that the researchers ensured that the successful outcomes of bariatric surgery didn't depend only on compliance with diet or medication but it also includes physical exercises that help to achieve the desirable weight loss. This result is agreed with Coen et al. who reported that two thirds of the studied patients successfully completed the recommended physical exercise interventions at the first six months after bariatric surgery ${ }^{[18]}$.

The majorities of the studied patients have good level of compliance with sleep and rest instructions after bariatric surgery. This is because patients stated that the recommended instructions about sleep and rest after bariatric surgery in the module was easy and simple to applied and followed. This enhances quality, duration of sleep and improves obstructive sleep apnea, and body posture.This result is consistent with Mello et al. who stated that bariatric surgery have demonstrated improvement in sleep disorders in people after surgery due to the impact of weight reduction ${ }^{[19]}$.

The majority of the studied patients have good level of compliance with follow up after bariatric surgery. This due to that patient recognized the importance of follow up visits during the educational session of lifestyle modification where it promote health and reduce the 
risk of weight regain. This finding agree with Dagan et al. who reported that most of studied people attend to follow-up visit at the first 3 months and 6 months and more than three quarters of them attend to follow-up after 12 month of bariatric surgeryl ${ }^{[20]}$.

There was statistically significant improvement post implementation of lifestyle modification module where, more than half of the studied people achieve fair level of total compliance. This study is agree with Dagan et al. who revealed that all of the studied patients have medium to high adherence to the major lifestyle recommendations during the first year following bariatric surgery ${ }^{[20]}$.

There was statistically significant improvement in patients' compliance with medication post implementation of lifestyle modification module. This could be attributed to patients' believes about the importance of prescribed medications and increased their awareness regarding benefits of compliance with vitamins and minerals supplements long life after surgery as a mean to compensate the essential element that have been lost due to small dietary meals intake as a result of surgery mechanism.

This result is consistent with Hood et al. who reported that medication adherence tends to be good in the early post-surgery period, $90 \%$ of patients taking supplements daily or every other day 5 months postsurgery ${ }^{[21]}$.

The perceiving of stress was improved among individuals with bariatric surgery because they convinced about the bad effect of stress on health and surgery outcomes, so that they practice and adhere to the stress relieving measures that explained by the researchers. This result go in the same line with Boniecka et al. who reported that, near half of the studied individuals had a moderate level of stress ${ }^{[22]}$.

Regarding Bariatric Analysis and Reporting Outcome System (BARO) and quality of life, therewas a statistically significant improvement post implementation of lifestyle modification module among studied people where (pre mean score $=1.57 \pm 0.89$ and post mean score $=5.00 \pm 1.47$ ). This finding is supported by Alkassis et al. who found that there was a statistically significant improvement in people quality of life domains after surgery and no one had a very poor or poor quality of life score, where (pre mean $=-0.33 \pm 0.93$ and post mean $=1.68 \pm 0.62)^{[23]}$.

\section{Conclusion}

Implementation of lifestyle modification module has positive effect on improving patients' compliance post-operative bariatric surgery regarding diet, physical exercise, sleep and rest instructions, follow up visits, medication adherence, stress perceiving, and quality of life.

Acknowledgements: Thanks to all patients who are agreed to participate in the study.

Ethical Clearance: Institutional ethical committee obtained for the study.

\section{Source of Funding: Self}

\section{Conflict of Interest: Nil}

\section{References}

1. World Health Organization. Obesity. Geneva: World Health Organisation; 2019. URL:https:// www.who.int/topics/obesity/en/[accessed 201907-01].

2. Blüher, M. Obesity: Global Epidemiology and Pathogenesis. Nature Reviews Endocrinology, 2019; 15(5): 288-298.

3. Parrott, J. M., Craggs-Dino, L., Faria, S. L., \& O'Kane, M. The Optimal Nutritional Programme for Bariatric and Metabolic Surgery. Current Obesity Reports, 2020; 1-13.

4. English, W. J., DeMaria, E. J., Hutter, M. M., Kothari, S. N., Mattar, S. G., Brethauer, S. A., \& Morton, J. M. American Society for Metabolic and Bariatric Surgery 2018 Estimate of Metabolic and Bariatric Procedures Performed in the United States. Surgeryfor Obesity and Related Diseases, 2020; 16(4): 557- 463.

5. Angrisani, L., Santonicola, A., Iovino, P., Vitiello, A., Zundel, N., Buchwald, H., \& Scopinaro, N. Bariatric Surgery and Endoluminal Procedures: IFSO Worldwide Survey 2014. Obesity Surgery, 2017; 27(9): 2279-2289.

6. Ariel-Donges, A. H., Oyama, C. K., \& Hood, M. M. Patient-Reported Short-Term Barriers to and Facilitators of Adherence to Behavioral Recommendations Following Bariatric Surgery. Bariatric Times, 2020; 17(7): 15-17.

7. Busetto, L., Dicker, D., Azran, C., Batterham, R. L., Farpour-Lambert, N., Fried, M., ... \& 
Schindler, K. Practical Recommendations of the Obesity Management Task Force of the European Association for the Study of Obesity for the PostBariatric Surgery Medical Management. Obesity Facts, 2017; 10(6): 597-632.

8. Good, V. S., \& Kirkwood, P. L. Advanced Critical Care Nursing (E-Book). 2nd ed. Elsevier, Canada, 2018; Pp. 734- 742.

9. Galioto, R., Gunstad, J., Heinberg, L. J., \& Spitznagel, M. B. Adherence and Weight Loss Outcomes in Bariatric Surgery: Does Cognitive Function Play A Role?. Obesity Surgery, 2013; 23(10): 1703-1710.

10. American Society for Metabolic and Bariatric Surgery. Life after Bariatric Surgery 2018. Available at: https://asmbs.org/patients/life-afterbariatric-surgery.[accessed on 16 August 2018 at 11: $17 \mathrm{am}]$.

11. Still, C. D., Benotti, P., Hangan, D., \& Zubair, F. Metabolic Complications, Nutritional Deficiencies, and Medication Management Following Metabolic Surgery. In Complications in Bariatric Surgery. Springer, Cham, 2018: Pp. 5-33.

12. Kumar, S., \& Gomes, R. M. (Eds.). Bariatric Surgical Practice Guide: Recommendations. Springer Singapore, 2017: P. 274. Thompson, K., Kulkarni, J., \& Sergejew, A. A. Reliability and Validity of a New Medication Adherence Rating Scale (MARS) for the Psychoses. Schizophrenia research, 2000; 42(3): 241-247.

13. Thompson, K., Kulkarni, J., \& Sergejew, A. A. Reliability and Validity of a New Medication Adherence Rating Scale (MARS) for the Psychoses. Schizophrenia research, 2000;42(3): 241-247.

14. Cohen, S., Kamarck, T., \& Mermelstein, R. A Global Measure of Perceived Stress. Journal of Health and Social Behavior, 1983; 24(4): 385-396.

15. Moorehead, M. K., Ardelt-Gattinger, E., Lechner, H., \& Oria, H. E. The Validation of the MooreheadArdelt Quality of Life Questionnaire II. Obesity Surgery, 2003;13(5): 684-692.
16. Kalarchian, M. A., Marcus, M. D., Courcoulas, A. P., Lutz, C., Cheng, Y., \& Sweeny, G. Structured Dietary Intervention to Facilitate Weight Loss After Bariatric Surgery: A Randomized, Controlled Pilot Study. Obesity, 2016; 24(9): 1906-1912.

17. Toussi, R., Fujioka, K., \& Coleman, K. J. Pre and Postsurgery Behavioral Compliance, Patient Health, and Post Bariatric Surgical Weight Loss. Obesity, 2009; 17(5): 996-1002.

18. Coen, P. M., Carnero, E. A., \& Goodpaster, B. H. Exercise and Bariatric Surgery: An Effective Therapeutic Strategy. Exercise and Sport Sciences Reviews, 2018; 46(4): 262.

19. Mello, M., Vasques, A. C. J., Pareja, J. C., Oliveira, M. D. S. D., Novaes, F. S., Chaim, É. A., \& Geloneze, B. Effect of Biliopancreatic Diversion on Sleep Quality and Day Time Sleepiness in Patients with Obesity and Type 2 Diabetes. Archives of Endocrinology and Metabolism, 2017;61(6): 623627.

20. Dagan, S. S., Keidar, A., Raziel, A., Sakran, N., Goitein, D., Shibolet, O., \& Zelber-Sagi, S. Do Bariatric Patients Follow Dietary and Lifestyle Recommendations during the First Postoperative Year?. Obesity Surgery, 2017; 27(9): 2258-2271.

21. Hood, M. M., Corsica, J., Bradley, L., Wilson, R., Chirinos, D. A., \& Vivo, A. Managing Severe Obesity: Understanding and Improving Ttreatment Adherence in Bariatric Surgery. Journal of Behavioral Medicine, 2016; 39(6): 1092-1103.

22. Boniecka, I., Wileńska, H., Jeznach-Steinhagen, A., Czerwonogrodzka-Senczyna, A., Sekuła, M., \& Paśnik, K. Stress as A Factor Contributing to Obesity in Patients Qualified for Bariatric SurgeryStudies in A Selected Group of Patients (A Pilot Study). Videosurgery and other Miniinvasive Techniques, 2017; 12(1): 60.

23. Alkassis, M., Haddad, F. G., Gharios, J., Noun, R., \& Chakhtoura, G. Quality of Life before and after Sleeve Gastrectomy in Lebanese Population. Journal of Obesity, 2019.1- 6. 